\title{
Are the sagittal cervical radiographic modifiers of the Ames-ISSG classification specific to adult cervical deformity?
}

\author{
Ziad Bakouny, MSc, ${ }^{1}$ Nour Khalil, MSc, ${ }^{1}$ Joeffroy Otayek, MSc, ${ }^{1}$ Aren Joe Bizdikian, MSc, ${ }^{1}$ \\ Fares Yared, MSc, ${ }^{1}$ Michel Salameh, MSc, ${ }^{1}$ Naji Bou Zeid, ${ }^{1}$ Ismat Ghanem, MD, MSc, ${ }^{1,2}$ \\ Khalil Kharrat, MD, ${ }^{1,2}$ Gaby Kreichati, MD, ${ }^{1,2}$ Renaud Lafage, MSc, ${ }^{3}$ Virginie Lafage, $\mathrm{PhD},{ }^{3}$ and \\ Ayman Assi, $\mathrm{PhD}^{1}$
}

\begin{abstract}
${ }^{1}$ Faculty of Medicine and ${ }^{2}$ Hôtel-Dieu de France Hospital, University of Saint-Joseph, Beirut, Lebanon; and ${ }^{3}$ Spine Division, Hospital for Special Surgery, New York, New York
\end{abstract}

\begin{abstract}
OBJECTIVE The Ames-International Spine Study Group (ISSG) classification has recently been proposed as a tool for adult cervical deformity evaluation. This classification includes three radiographic cervical sagittal modifiers that have not been evaluated in asymptomatic adults. The aim of this study was to determine whether the sagittal radiographic modifiers described in the Ames-ISSG cervical classification are encountered in asymptomatic adults without alteration of health-related quality of life (HRQOL).

METHODS The authors conducted a cross-sectional study of subjects with an age $\geq 18$ years and no cervical or backrelated complaints or history of orthopedic surgery. All subjects underwent full-body biplanar radiographs with the measurement of cervical, segmental, and global alignment and completed the SF-36 HRQOL questionnaire. Subjects were classified according to the sagittal radiographic modifiers (chin-brow vertical angle [CBVA], mismatch between T1 slope and cervical lordosis [TS-CL], and C2-7 sagittal vertical axis [CSVA]) of the Ames-ISSG classification for cervical deformity, which also includes a qualitative descriptor of cervical deformity, the modified Japanese Orthopaedic Association (mJOA) myelopathy score, and the Scoliosis Research Society (SRS)-Schwab classification for spinal deformity assessment. Characteristics of the subjects classified by the different modifier grades were compared.
\end{abstract}

RESULTS One hundred forty-one asymptomatic subjects (ages 18-59 years, 71 females) were enrolled in the study. Twenty-seven (19.1\%) and 61 (43.3\%) subjects were classified as grade 1 in terms of the TS-CL and CBVA modifiers, respectively. Ninety-eight (69.5\%) and $4(2.8 \%)$ were grade 2 for these same respective modifiers. One hundred thirty-six $(96.5 \%)$ subjects had at least one modifier at grade 1 or 2 . There was a significant relationship between patient age and grades of TS-CL $(p<0.001$, Cramer's V $[C V]=0.32)$ and CBVA $(p=0.04, C V=0.22)$ modifiers. The HRQOL, global alignment, and segmental alignment parameters were similar among the subjects with different modifier grades $(p>0.05)$. CONCLUSIONS The CBVA and TS-CL radiographic modifiers of the Ames-ISSG classification do not seem to be specific to subjects with cervical deformities and can occur in asymptomatic subjects without alteration in HRQOL.

https://thejns.org/doi/abs/10.3171/2018.2.SPINE171285

KEYWORDS Ames-ISSG classification; cervical alignment; health-related quality of life; asymptomatic adults; sagittal alignment; deformity

$\mathrm{A}$ DULT spinal deformity (ASD) evaluation and treatment have greatly benefited from the classification devised by Schwab et al., which classifies ASD based on the mismatch between pelvic incidence and lumbar lordosis, pelvic tilt, and C7-S1 sagittal vertical axis
(SVA) ${ }^{11}$ Similar to classifications in other fields, the Scoliosis Research Society (SRS)-Schwab classification has allowed more systematic reporting of the findings of ASD researchers, with a number of studies related to both the treatment and evaluation of ASD subsequently published

ABBREVIATIONS ASD = adult spinal deformity; $\mathrm{BMI}=$ body mass index; $\mathrm{CBVA}=$ chin-brow vertical angle; $\mathrm{CL}=\mathrm{cervical}$ lordosis; $\mathrm{cSVA}=\mathrm{C} 2-7 \mathrm{SVA}$; $\mathrm{HRQOL}=\mathrm{health}$ related quality of life; ISSG = International Spine Study Group; mJOA = modified Japanese Orthopaedic Association; PI-LL = pelvic incidence-lumbar lordosis; SRS = Scoliosis Research Society; SVA = sagittal vertical axis; TS-CL = mismatch between T1 slope and cervical lordosis.

SUBMITTED November 24, 2017. ACCEPTED February 21, 2018.

INCLUDE WHEN CITING Published online July 27, 2018; DOI: 10.3171/2018.2.SPINE171285. 
based on this classification. ${ }^{6,8,12}$ Recently, there has been increased interest in cervical deformity evaluation, and a number of radiographic parameters analogous to those of global sagittal alignment evaluation have been developed. ${ }^{7,10,13}$

A Delphi consensus-based classification for adult cervical deformities has recently been proposed and shown to be reproducible. ${ }^{2}$ This classification encompasses a qualitative description of cervical deformity, a clinical myelopathy score modifier (modified Japanese Orthopaedic Association [mJOA] scale score), and the SRS-Schwab classification as a modifier for spinal deformity assessment, as well as the three following sagittal cervical radiographic modifiers: chin-brow vertical angle (CBVA), mismatch between T1 slope and cervical lordosis (TS-CL), and C2-7 SVA (cSVA). Cutoffs for each of the three latter modifiers that classify subjects into grades 0,1 , or 2 were determined in the classification. ${ }^{2}$

Normal adult sagittal cervical alignment has recently been shown to be very heterogeneous. In fact, while asymptomatic subjects have been classically presumed to present with lordotic alignment in the cervical spine, asymptomatic adults have recently been shown to present with both cervical lordosis and cervical kyphosis. ${ }^{10}$ The Ames-International Spine Study Group (ISSG) classification's sagittal cervical alignment modifiers describe cervical deformity patients as having a nonhorizontal gaze, an anteriorly projected C-2 vertebra, and a cervical curvature that does not sufficiently compensate for the TS. ${ }^{2}$ However, there have been no studies to determine whether the cervical anomalies described in the Ames-ISSG classification overlap with the variations in cervical alignment in asymptomatic subjects.

The objective of this study was to determine if the sagittal radiographic modifiers described in the Ames-ISSG cervical classification are encountered in asymptomatic adults without alteration of health-related quality of life (HRQOL).

\section{Methods \\ Study Design}

This is an institutional review board (IRB)-approved cross-sectional observational study of the cervical radiographic parameters of the Ames-ISSG cervical classification in asymptomatic adults. The inclusion criteria were an age $\geq 18$ years and the absence of cervical or back-related complaints. The exclusion criterion was a history of surgery to the pelvis or spine. Most of the asymptomatic adults included in the study were recruited from the university at which the study was conducted (students, faculty, or staff). All subjects signed a written informed-consent form.

\section{Data Acquisition}

Demographic characteristics were collected for each subject: sex, age, weight, height, and body mass index (BMI). Each subject underwent full-body biplanar radiographic examination (EOS Imaging) while standing in the standardized free-standing position during image acquisition. ${ }^{3,4}$ All subjects were instructed to look straight ahead during radiographic acquisition. A single operator-an orthopedic resident who had been trained in performing these measurements-digitally analyzed all lateral radiographs using Surgimap ${ }^{1}$ (Nemaris Inc.), which had been previously validated and its cervical measurements found to be reliable. ${ }^{5}$ The following parameters were measured using Surgimap: T1-12 kyphosis, L1-5 lordosis, pelvic parameters (pelvic incidence [PI], sacral slope [SS], pelvic tilt [PT]), C7-S1 SVA, cervical lordosis (CL) angle, T1 slope (TS), radiographic CBVA, and cSVA. The CL angle was considered to have a positive value when the cervical spine was lordotic and a negative value when kyphotic. The TS-CL was computed as the arithmetic difference between the TS and the CL angle. These parameters are represented in Fig. 1.

All subjects completed the SF-36 HRQOL questionnaire, and the raw data were adjusted to previously published local normative data. ${ }^{9}$ The four physical components (physical functioning, role limitations due to physical health, bodily pain, and general health) and four mental components (vitality, social functioning, role limitations due to emotional problems, and mental health) of the SF-36, along with their respective summary components, were calculated for each subject.

\section{Statistical Analysis}

All quantitative variables were tested for normality using the Shapiro-Wilk test and for equality of variance using Levene's test.

All subjects were classified by grades $0-2$ according to the sagittal cervical radiographic modifiers of the AmesISSG classification (Table 1 and Fig. 1). ${ }^{2}$ Furthermore, to determine whether the cervical alignment modifiers are more frequently encountered in certain age groups, subjects were subdivided into the following age groups: $18-30,31-45$, and $46-60$ years. The number of subjects presenting with each type of radiographic modifier was determined for each age group, and comparisons between age groups were made using Fisher's exact test. Effect sizes for the between-age-group differences in the proportions of radiographic modifiers were evaluated using Cramer's V (CV).

To determine whether the presence of Ames-ISSG sagittal cervical modifiers is related to other subject characteristics such as demographics, HRQOL, global alignment parameters, and segmental alignment parameters, the Mann-Whitney U-test was used to compare the parameters for each modifier between subjects graded 1 or 2 and those graded 0. Furthermore, SRS-Schwab classification modifier grades ${ }^{11}$ and sex distributions between Ames-ISSG modifier grades were compared using Fisher's exact test.

The significance level was set at 0.05 . Statistical analysis was performed using IBM SPSS Statistics version 20.0 (IBM Corp.) and Xlstat version 2016.05.3 (Addinsoft).

\section{Results}

\section{Subject Demographics}

One hundred forty-one asymptomatic adults (ages 1859 years, 70 males and 71 females) were recruited for this study. The demographic characteristics of the sample are presented in Table 2. 


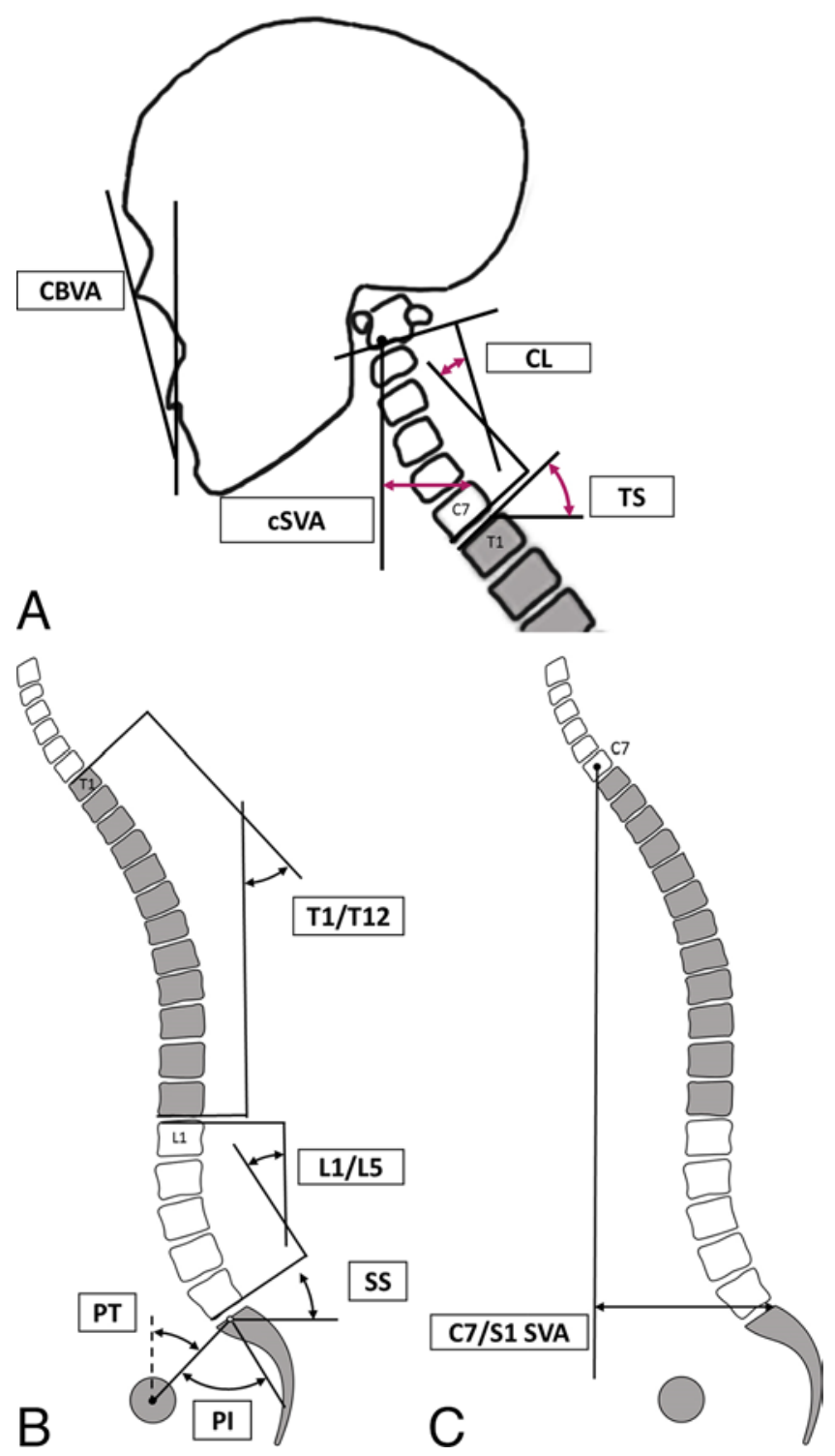

FIG. 1. Representation of the parameters of sagittal cervical (A), segmental (B), and global alignment (C). CBVA = chin-brow vertical angle; $\mathrm{CL}=$ cervical lordosis angle; $\mathrm{CSVA}=\mathrm{C} 2-7$ sagittal vertical axis; $\mathrm{C7/S1}$ SVA = C7-S1 SVA; L1/L5 = L1-5 lordosis; PI = pelvic incidence; $\mathrm{PT}=$ pelvic tilt; SS = sacral slope; $\mathrm{TS}=\mathrm{T} 1$ slope; $\mathrm{T} 1 / \mathrm{T} 12=\mathrm{T} 1-12$ kyphosis . Figure is available in color online only.

\section{Prevalence of Cervical Ames-ISSG Modifiers}

The distribution of subjects by the cSVA modifier revealed that $140(99.3 \%)$ subjects were classified as grade $0,1(0.7 \%)$ as grade 1 , and none as grade 2. Sixteen $(11.3 \%)$ subjects were classified as grade 0 for TS-CL, $27(19.1 \%)$ as grade 1, $98(69.5 \%)$ as grade 2 . Seventy-six (53.9\%) subjects were classified as grade 0 for the CBVA modifier, $61(43.3 \%)$ as grade 1 , and $4(2.8 \%)$ as grade 2. Among subjects graded 1 for the CBVA modifier, 34 (24.1\%) had a negative CBVA and 27 (19.1\%) had a positive CBVA. All subjects graded 2 for the CBVA modifier had a negative CBVA. Five (3.5\%) subjects were classified as grade 0 for all sagittal cervical modifiers, 136 (96.5\%)
TABLE 1. Thresholds of the radiographic cervical modifiers of the Ames-ISSG classification

\begin{tabular}{clll}
\hline Grade & \multicolumn{1}{c}{ CBVA } & \multicolumn{1}{c}{ TS-CL } & \multicolumn{1}{c}{ CSVA } \\
\hline 0 & $1^{\circ}$ to $10^{\circ}$ & $<15^{\circ}$ & $<4 \mathrm{~cm}$ \\
\hline 1 & $-10^{\circ}$ to $0^{\circ}$ or $11^{\circ}$ to $25^{\circ}$ & $15^{\circ}$ to $20^{\circ}$ & 4 to $8 \mathrm{~cm}$ \\
\hline 2 & $<-10^{\circ}$ or $>25^{\circ}$ & $>20^{\circ}$ & $>8 \mathrm{~cm}$ \\
\hline
\end{tabular}

TABLE 2. Demographic characteristics of the study sample

\begin{tabular}{ccc}
\hline Parameter & Value & Range \\
\hline No. of subjects & 141 & \\
\hline Sex $(\mathrm{F} / \mathrm{M})$ & $71 / 70$ & \\
\hline Age $(\mathrm{yrs})$ & $29.3 \pm 11.1$ & $18-59$ \\
\hline Height $(\mathrm{m})$ & $1.69 \pm 0.10$ & $1.48-1.89$ \\
\hline Weight $(\mathrm{kg})$ & $70.6 \pm 14.4$ & $41.5-108.0$ \\
\hline BMl $\left(\mathrm{kg} / \mathrm{m}^{2}\right)$ & $24.4 \pm 3.6$ & $17.6-36.1$ \\
\hline \multicolumn{2}{l}{ Values reported as the mean \pm standard deviation, unless indicated otherwise. }
\end{tabular}

subjects had at least one modifier at grade 1 or 2 , and 55 (39.0\%) subjects had at least two modifiers at grade 1 or 2 . One hundred two (72.3\%) subjects had at least one modifier at grade 2 .

\section{Relationships Between Cervical Ames-ISSG Modifiers and Patient Age}

The relationship between patient age and cervical modifiers is represented in Fig. 2. A significant relationship was found between age and grades of the TS-CL ( $<<$ $0.001, \mathrm{CV}=0.32$; Fig. 2A). Eighty-two percent of younger subjects (18-30 years) were found to have a TS-CL $>20^{\circ}$ (grade 2), whereas only $30 \%$ of the older subjects (46-60 years) were categorized as grade 2 . A significant relationship was also found between age and grades of the CBVA modifier ( $\mathrm{p}=0.04, \mathrm{CV}=0.22$; Fig. $2 \mathrm{~B}$ ). Thirty-five percent of older subjects (46-60 years) had a CBVA between $1^{\circ}$ and $10^{\circ}$ (grade 0 ) compared to $57 \%$ of younger subjects (18-30 years and 31-45 years). No significant relationship between age and the cSVA modifier was found $(\mathrm{p}=1.00$, $\mathrm{CV}=0.06$; Fig. 2C).

\section{Characteristics of Subjects by Cervical ISSG Modifier}

Demographics and cervical alignment parameters were compared between the different grades of the CBVA and TS-CL modifiers (Table 3). Demographic characteristics (sex, height, weight, BMI) were similar across grades for both the CBVA and TS-CL modifiers. The TS was similar between subjects graded 0 and those graded 1 or 2 for either the TS-CL or the CBVA modifier. However, CL, TS-CL, CBVA, and cSVA were significantly different between subjects graded 0 and those graded 1 or 2 for the TS-CL modifier. In contrast, CL, TS-CL, CBVA, and cSVA did not significantly differ between subjects graded 0 and those graded either 1 or 2 for the CBVA modifier.

A comparison of global and segmental sagittal align- 
T1S-CL modifier : $\mathrm{p}<0.001 ; \mathrm{CV}=\mathbf{0 . 3 2}$
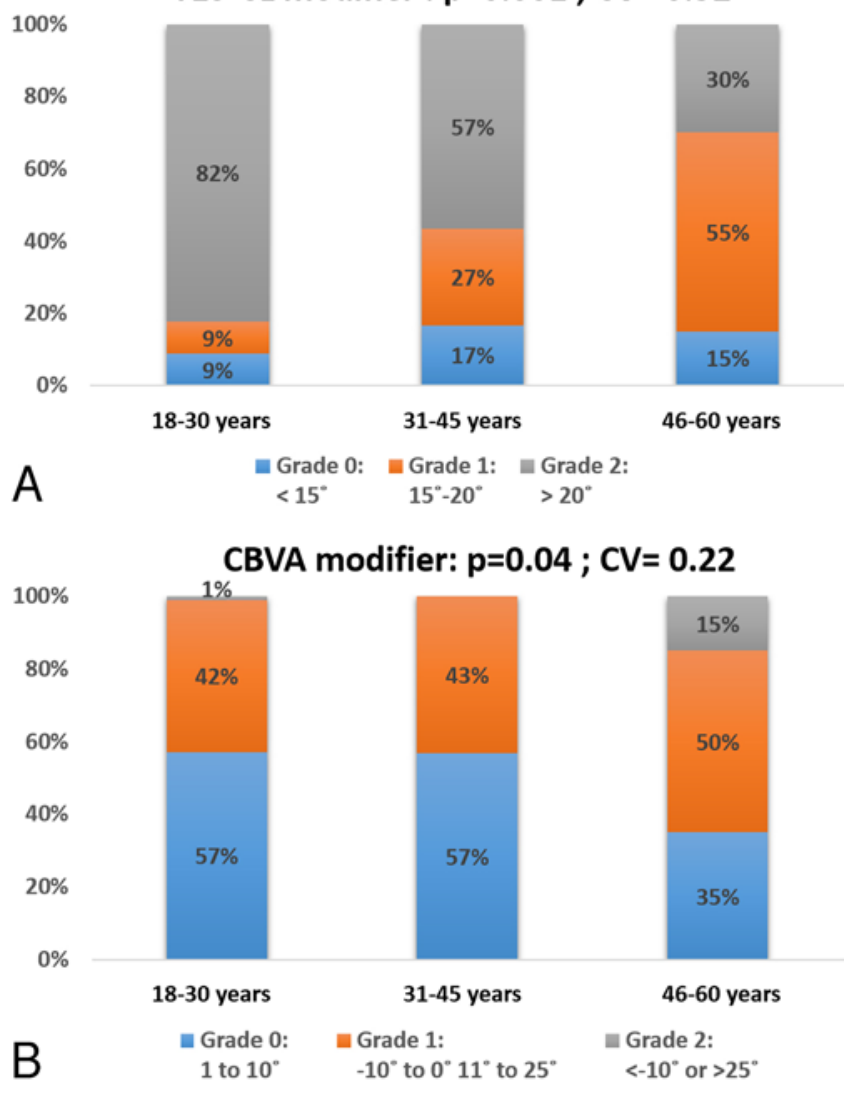

cSVA modifier: $p=1.00 ; C V=0.06$

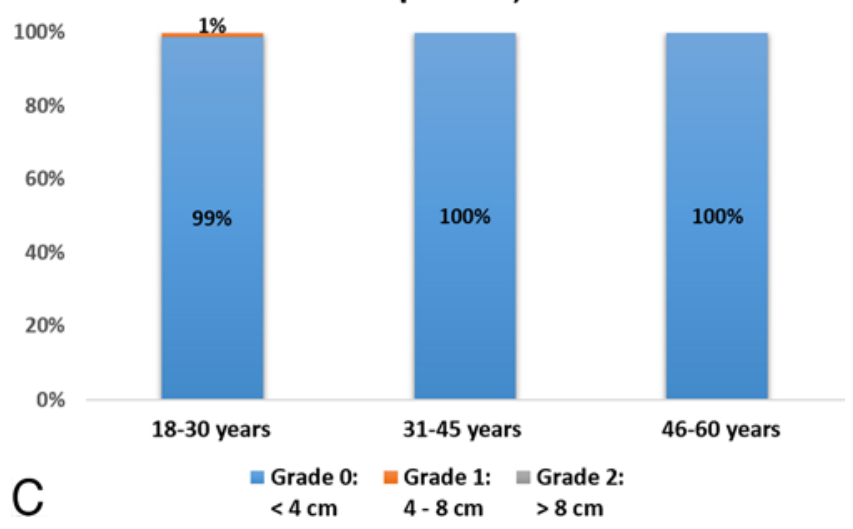

FIG. 2. Distribution by age groups for the TS-CL (A), CBVA (B), and CSVA (C) modifiers of the Ames-ISSG classification. CV = Cramer's V. Figure is available in color online only.

ment parameters between modifier grades is illustrated in Fig. 3. Only C7-S1 SVA and L1-5 tended to differ between subjects graded 0 and those graded 1 or 2 for the CBVA modifier (Fig. 3 lower); however, this difference did not reach the threshold for statistical significance ( $p=0.073$ and 0.063 , respectively). In fact, none of the global and segmental sagittal alignment parameters significantly differed between subjects graded 0 and those graded 1 or 2 for either the TS-CL or the CBVA modifiers.
The relationship between subjects grouped into the sagittal cervical modifier grades of the Ames-ISSG classification and those grouped into the sagittal alignment modifier grades of the SRS-Schwab classification is illustrated in Fig. 4. No statistically significant relationship was found between the grades of any of the SRS-Schwab classification modifiers and the Ames-ISSG classification grades for the TS-CL and CBVA modifiers.

All SF-36 components were similar $(\mathrm{p}>0.05)$ between grades for both the TS-CL (Fig. 5 upper) and CBVA modifiers (Fig. 5 lower). Since only one subject was found to have a cSVA modifier at either grade 1 or 2, the comparison of SF-36 components, demographics, and global, segmental, or cervical alignments across the grades for this modifier was not possible.

\section{Discussion}

This is the first study to evaluate the radiographic modifiers of the Ames-ISSG classification in an asymptomatic adult population. Modifiers at grades 1 or 2 were very frequently encountered among asymptomatic adults. While the TS-CL modifier was more frequently graded 1 or 2 in younger subjects, grades 1 or 2 of the CBVA modifier were more prevalent in older subjects. The subjects with these radiographic anomalies did not have any alteration in HRQOL.

In this study, $96.5 \%$ of asymptomatic adults with no back- or neck-related complaints or symptoms were found to have at least one sagittal radiographic modifier of the Ames-ISSG classification at grade 1 or above and $72.3 \%$ at grade 2 . The two modifiers most frequently graded 1 or 2 in asymptomatic adults were the CBVA and TS-CL. Among the sagittal cervical alignment modifiers, only cSVA was occasionally graded as either 1 or $2(0.7 \%)$ in asymptomatic adults. These findings strongly suggest that the CBVA and TS-CL radiographic modifier thresholds, as described in the Ames-ISSG classification, are not specific to adult cervical deformity.

The TS-CL modifier was found to be graded 1 or 2 (especially grade 2 ) more frequently among subjects aged 18-30 years than among older subjects. The TS-CL parameter represents compensation of the downward slope of T1 by the cervical lordotic curvature, ${ }^{2,7}$ analogously to the pelvic incidence-lumbar lordosis (PI-LL) parameter, which represents compensation of the downward slope of the sacral plate by the lumbar lordotic curvature. ${ }^{7}$ A TSCL parameter above $15^{\circ}$, corresponding to a grade 1 or 2 , would therefore represent under-compensation of the slope of T1 (since the increased TS would not have been accompanied by an increase in CL). In fact, subjects with such a modifier were found to have a cervical curvature that was on average kyphotic $\left(\mathrm{CL}<0^{\circ}\right)$. These subjects consequently presented with a significantly larger cSVA (more anterior position of $\mathrm{C}-2$ relative to $\mathrm{C}-7$ ) and larger CBVA (more downward line of vision) than those in subjects graded 0 for the TS-CL modifier (Table 3). Therefore, while the PI-LL has been shown to increase with age,${ }^{6} \mathrm{TS}-$ CL was more frequently found to be larger (grade 1 or 2 ) in younger subjects in the present study.

In contrast, the CBVA modifier was found to be graded 
TABLE 3. Demographic and sagittal cervical alignment characteristics for different grades of CBVA and TS-CL

\begin{tabular}{|c|c|c|c|c|c|c|}
\hline \multirow[b]{2}{*}{ Parameter } & \multicolumn{3}{|c|}{ TS-CL Modifier } & \multicolumn{3}{|c|}{ CBVA Modifier } \\
\hline & Grade 0 & Grade 1 or 2 & $p$ Value & Grade 0 & Grade 1 or 2 & p Value \\
\hline No. of subjects & 16 & 125 & - & 76 & 65 & - \\
\hline $\operatorname{Sex}(F / M)$ & $10 / 6$ & $61 / 64$ & 0.427 & $36 / 35$ & $40 / 30$ & 0.501 \\
\hline Height (m) & $1.69 \pm 0.10$ & $1.70 \pm 0.10$ & 0.726 & $1.69 \pm 0.09$ & $1.70 \pm 0.10$ & 0.731 \\
\hline Weight (kg) & $69.4 \pm 12.3$ & $70.7 \pm 14.7$ & 0.721 & $70.6 \pm 15.3$ & $70.6 \pm 13.4$ & 0.992 \\
\hline $\mathrm{BMI}\left(\mathrm{kg} / \mathrm{m}^{2}\right)$ & $24.3 \pm 3.1$ & $24.4 \pm 3.7$ & 0.982 & $24.4 \pm 3.6$ & $24.4 \pm 3.7$ & 0.780 \\
\hline $\operatorname{TS}\left({ }^{\circ}\right)$ & $23.8 \pm 8.4$ & $25.9 \pm 8.0$ & 0.201 & $26.6 \pm 8.0$ & $24.7 \pm 8.1$ & 0.174 \\
\hline $\mathrm{CL}$ angle $\left({ }^{\circ}\right)$ & $14.0 \pm 11.6$ & $-0.7 \pm 11.3$ & $<0.001$ & $0.9 \pm 10.8$ & $1.0 \pm 13.8$ & 0.916 \\
\hline TS-CL $\left({ }^{\circ}\right)$ & $9.8 \pm 4.9$ & $26.7 \pm 7.6$ & $<0.001$ & $25.7 \pm 7.3$ & $23.7 \pm 10.7$ & 0.090 \\
\hline $\operatorname{CBVA}\left({ }^{\circ}\right)$ & $0.4 \pm 8.4$ & $4.8 \pm 6.6$ & 0.044 & $5.6 \pm 2.9$ & $2.8 \pm 9.5$ & 0.084 \\
\hline $\operatorname{cSVA}\left({ }^{\circ}\right)$ & $12.8 \pm 6.4$ & $22.1 \pm 7.6$ & $<0.001$ & $21.9 \pm 7.3$ & $20.0 \pm 8.7$ & 0.217 \\
\hline
\end{tabular}

$-=$ not applicable.

Values reported as the mean \pm standard deviation unless indicated otherwise. Boldface type indicates statistical significance.

1 or 2 significantly more frequently in older subjects than in younger ones, with $65 \%$ of subjects between 46 and 60 years of age having either a grade 1 or a grade 2 CBVA modifier. The CBVA parameter represents the line of sight; a CBVA close to zero represents a horizontal line of sight, whereas increasingly positive and negative values rep- resent a line of sight that is increasingly deviant. ${ }^{2}$ Therefore, the thresholds in the Ames-ISSG classification for grades 1 and 2 CBVA are both positive and negative since both would represent deviations from a horizontal line of sight. ${ }^{2,7}$ Therefore, subjects with opposite cervical patterns, producing either a negative or a positive CBVA, could be

Global sagittal alignment parameters of subjects divided by CBVA modifier
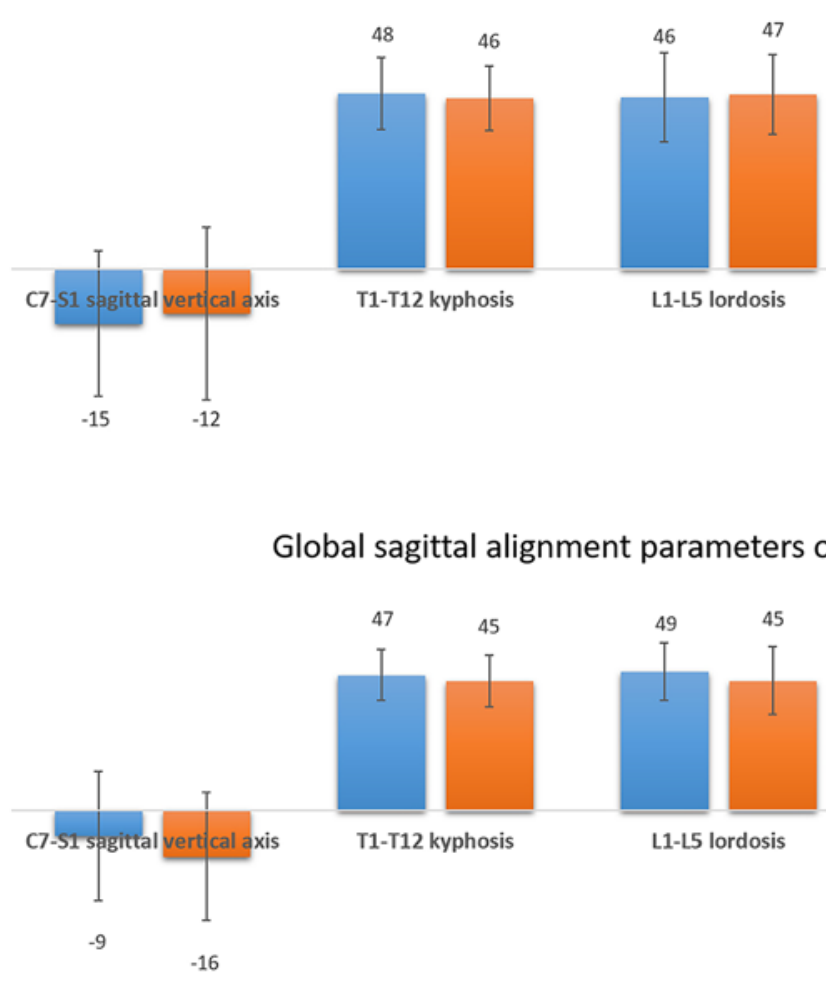

L1-L5 lordosis

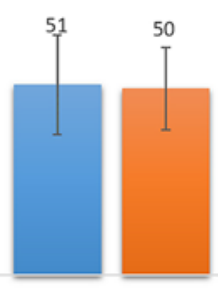

Pelvic incidence

Sacral slope
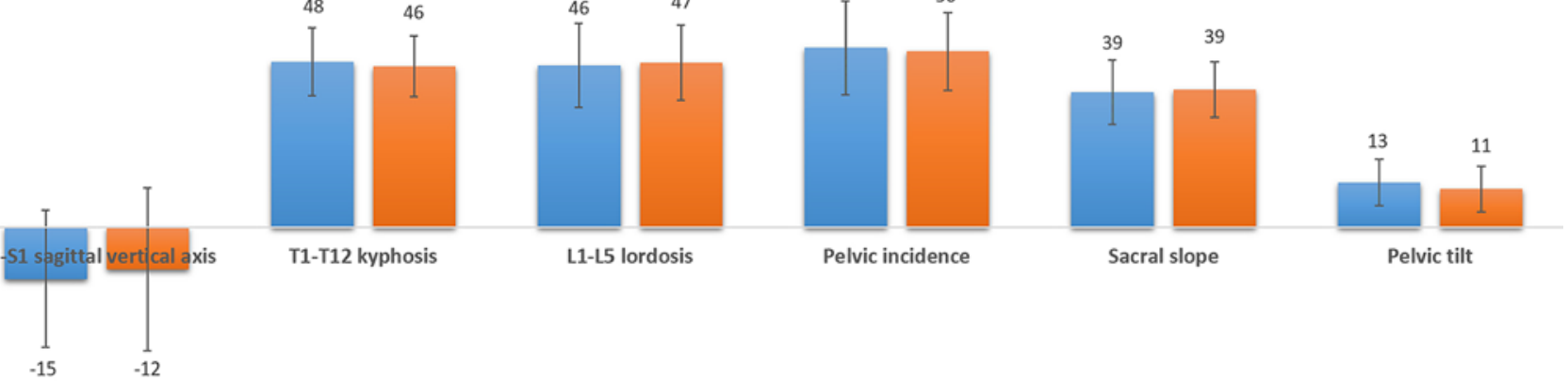

(n)

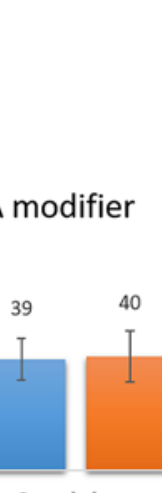

Pelvic tilt

Grade 0 Grades 1 or 2

FIG. 3. Global sagittal alignment parameters of subjects divided by the TS-CL modifier (upper) and CBVA modifier (lower) of the Ames-ISSG. Figure is available in color online only. 


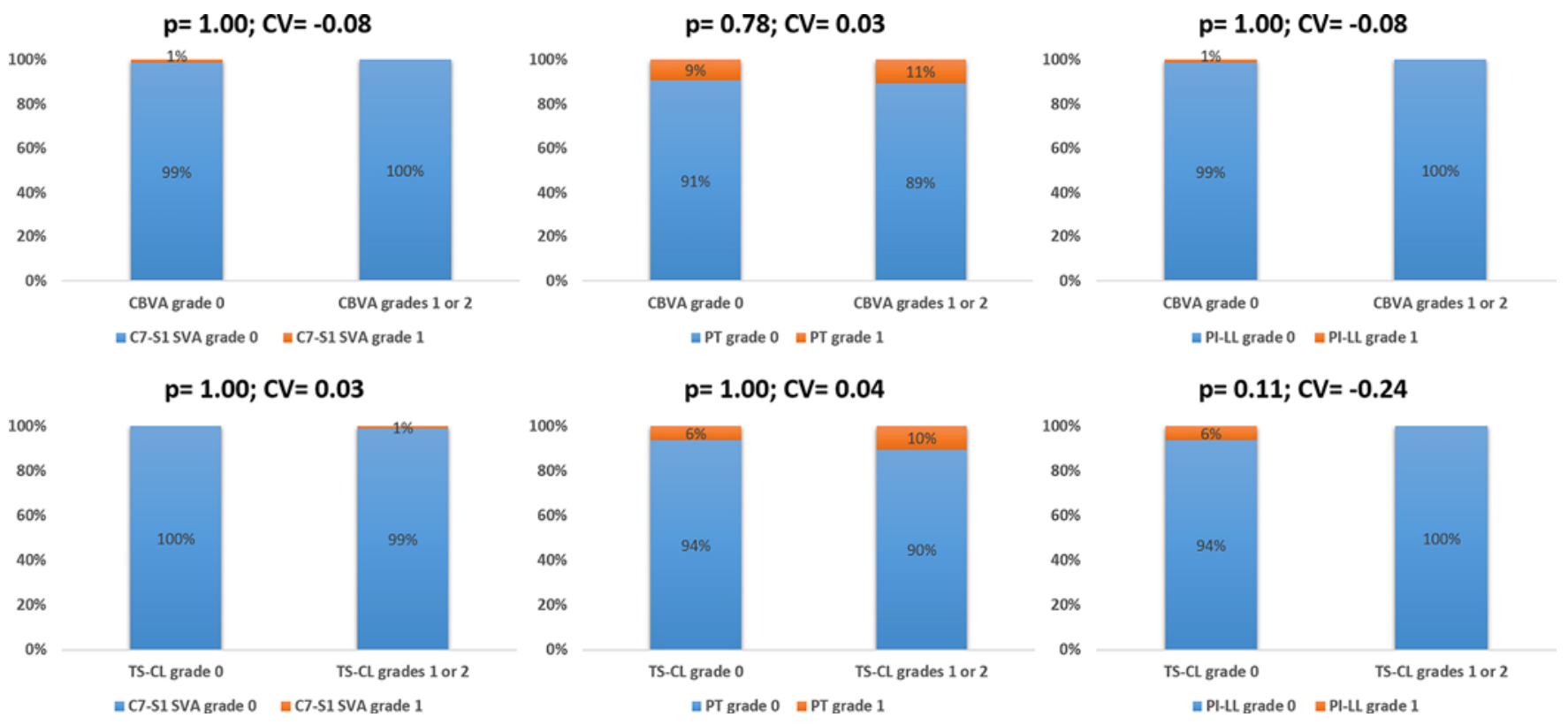

FIG. 4. Distribution of SRS-Schwab sagittal modifier grades by the Ames-ISSG grades for CBVA modifier (upper) and TS-CL modifier (lower). Figure is available in color online only.

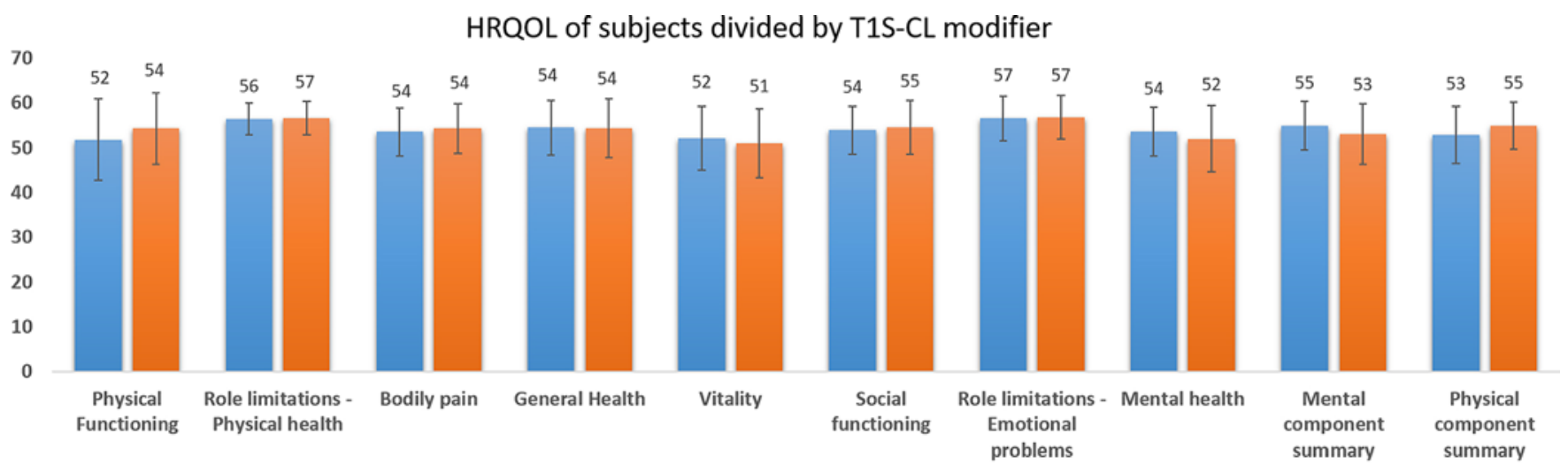

HRQOL of subjects divided by CBVA modifier

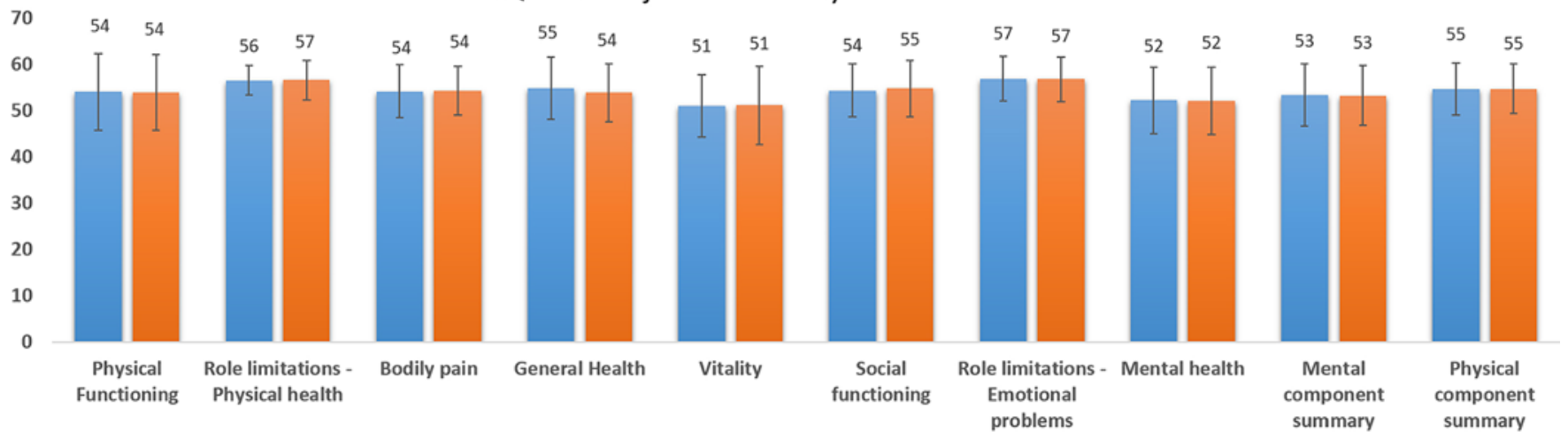

Grade 0 Grades 1 or 2

FIG. 5. The HRQOL for subjects divided by the TS-CL (upper) and CBVA (lower) modifiers of the Ames-ISSG classification. Figure is available in color online only. 
classified in the same grade of the CBVA modifier. These definitions of the thresholds for CBVA would explain why none of the averages of the cervical parameters significantly differed between subjects graded 1 or 2 and those graded 0 for the CBVA modifier. In fact, even the average CBVA itself did not significantly differ between the two groups but was found to have much larger variation in the group graded 1 or 2 , represented by its standard deviation of 9.5 as compared to just 2.9 in the CBVA grade 0 group (Table $3)$. The heterogeneity of subjects graded either 1 or 2 for the CBVA modifier suggests that the classification should grade subjects as $1+\left(11^{\circ}\right.$ to $\left.25^{\circ}\right)$ or $1-\left(-10^{\circ}\right.$ to $\left.0^{\circ}\right)$ instead of simply grade 1 and as grades $2-\left(<-10^{\circ}\right)$ or $2+\left(>25^{\circ}\right)$ instead of simply grade 2 .

Subjects with grade 1 or 2 CBVA or TS-CL modifiers did not differ in their segmental or global alignments compared to subjects classified as grade 0 for these modifiers (Fig. 3). Furthermore, no significant relationship was found between the distribution of the sagittal modifier grades of the SRS-Schwab classification and the grades of the Ames-ISSG CBVA or TS-CL modifiers (Fig. 4). These results suggest that the occurrence of sagittal cervical modifiers of the Ames-ISSG classification in asymptomatic adults is independent of the global and segmental alignments of these subjects.

Importantly, while the modifiers of the SRS-Schwab classification for subjects with ASD have been shown to be highly correlated to HRQOL, ${ }^{11}$ subjects graded 1 or 2 for either the CBVA or TS-CL modifier were found to have an HRQOL similar to that in subjects graded 0 for these modifiers (Fig. 5). Therefore, grades 1 or 2 of these modifiers do not seem to be related to a decreased HRQOL, at least in this patient sample.

A limitation of this study is its lack of a matched group with adult cervical deformity. If such a group of patients had been included, the value of the radiographic modifiers of the Ames-ISSG classification as tools to distinguish between adult cervical deformity patients and asymptomatic adults would have been more precisely evaluated. A second limitation of this study is that patients' QOL was only assessed using the SF-36 questionnaire and that no data from a disease-specific questionnaire were available (such as the Neck Disability Index). A third possible limitation of this study is that the included asymptomatic subjects were trusted to provide truthful and accurate information regarding their medical and surgical history as well as their asymptomatic state. Some subjects may have had unstated motivations when participating in this study (e.g., being symptomatic and being included in the study to get radiographs to rule out cervical pathology). However, all subjects were explicitly asked about the presence of cervical or back-related symptoms, and a medical and surgical history was meticulously taken for each subject. Furthermore, none of the included subjects were found to have a markedly altered QOL per the SF-36 questionnaire.

\section{Conclusions}

In summary, this study suggests that the CBVA and TSCL radiographic modifiers of the Ames-ISSG classification are not specific to subjects with cervical deformities and can occur in asymptomatic subjects without an altera- tion in HRQOL. Therefore, the evaluation of patients with cervical deformity should not be limited to radiography but would also need to include an evaluation of cervical mechanical and myelopathy symptoms, as outlined in the Ames-ISSG classification. Furthermore, the radiographic thresholds defining grade 0 for these modifiers do not seem to be representative of the cervical alignment of asymptomatic adults and thus may not be useful as objectives for cervical realignment surgery. Future studies should attempt to identify alternative radiographic parameters or alternative thresholds for the parameters included in the Ames-ISSG classification that could better discriminate between subjects with cervical deformity and asymptomatic subjects.

\section{References}

1. Akbar M, Terran J, Ames CP, Lafage V, Schwab F: Use of Surgimap Spine in sagittal plane analysis, osteotomy planning, and correction calculation. Neurosurg Clin N Am 24:163-172, 2013

2. Ames CP, Smith JS, Eastlack R, Blaskiewicz DJ, Shaffrey CI, Schwab F, et al: Reliability assessment of a novel cervical spine deformity classification system. J Neurosurg Spine 23:673-683, 2015

3. Horton WC, Brown CW, Bridwell KH, Glassman SD, Suk SI, Cha CW: Is there an optimal patient stance for obtaining a lateral 36" radiograph? A critical comparison of three techniques. Spine (Phila Pa 1976) 30:427-433, 2005

4. Janssen MM, Drevelle X, Humbert L, Skalli W, Castelein RM: Differences in male and female spino-pelvic alignment in asymptomatic young adults: a three-dimensional analysis using upright low-dose digital biplanar X-rays. Spine (Phila Pa 1976) 34:E826-E832, 2009

5. Lafage R, Ferrero E, Henry JK, Challier V, Diebo B, Liabaud $\mathrm{B}$, et al: Validation of a new computer-assisted tool to measure spino-pelvic parameters. Spine J 15:2493-2502, 2015

6. Lafage R, Schwab F, Challier V, Henry JK, Gum J, Smith J, et al: Defining spino-pelvic alignment thresholds: should operative goals in adult spinal deformity surgery account for age? Spine (Phila Pa 1976) 41:62-68, 2016

7. Lee SH, Kim KT, Seo EM, Suk KS, Kwack YH, Son ES: The influence of thoracic inlet alignment on the craniocervical sagittal balance in asymptomatic adults. J Spinal Disord Tech 25:E41-E47, 2012

8. Moal B, Lafage V, Smith JS, Ames CP, Mundis G, Terran JS, et al: Clinical improvement through surgery for adult spinal deformity: what can be expected and who is likely to benefit most? Spine Deform 3:566-574, 2015

9. Sabbah I, Drouby N, Sabbah S, Retel-Rude N, Mercier M: Quality of life in rural and urban populations in Lebanon using SF-36 health survey. Health Qual Life Outcomes 1:30, 2003

10. Scheer JK, Tang JA, Smith JS, Acosta FL Jr, Protopsaltis TS, Blondel B, et al: Cervical spine alignment, sagittal deformity, and clinical implications: a review. J Neurosurg Spine 19:141-159, 2013

11. Schwab F, Ungar B, Blondel B, Buchowski J, Coe J, Deinlein D, et al: Scoliosis Research Society-Schwab adult spinal deformity classification: a validation study. Spine (Phila Pa 1976) 37:1077-1082, 2012

12. Smith JS, Klineberg E, Schwab F, Shaffrey CI, Moal B, Ames CP, et al: Change in classification grade by the SRSSchwab Adult Spinal Deformity Classification predicts impact on health-related quality of life measures: prospective analysis of operative and nonoperative treatment. Spine (Phila Pa 1976) 38:1663-1671, 2013 
13. Smith JS, Shaffrey CI, Fu KMG, Scheer JK, Bess S, Lafage $\mathrm{V}$, et al: Clinical and radiographic evaluation of the adult spinal deformity patient. Neurosurg Clin N Am 24:143-156, 2013

\section{Disclosures}

This study was supported by the research council of the University of Saint-Joseph (grant no. FM189). The funding institution did not interfere in the study design; in the collection, analysis and interpretation of data; in the writing of the report; and in the decision to submit the article for publication.

\section{Author Contributions}

Conception and design: Assi, Bakouny. Acquisition of data:
Bakouny, Khalil, Otayek, Bizdikian, Yared, Salameh, Bou Zeid. Analysis and interpretation of data: Bakouny, Khalil, Otayek. Drafting the article: Bakouny, Khalil, Otayek. Critically revising the article: Assi, Ghanem, Kharrat, Kreichati, R Lafage, V Lafage. Reviewed submitted version of manuscript: Khalil, Ghanem, Kharrat, Kreichati, R Lafage, V Lafage. Statistical analysis: Bakouny, R Lafage. Administrative/technical/material support: Assi, Ghanem. Study supervision: Assi.

\section{Correspondence}

Ayman Assi: University of Saint-Joseph, Beirut, Lebanon. ayman. assi@gmail.com; ayman.assi@usj.edu.lb. 